\title{
REFLEXÕES SOBRE A NOÇÃO DE EXPERIÊNCIA NA OBRA DE WALTER BENJAMIN
}

\author{
REFLECTIONS ON THE NOTION OF EXPERIENCE \\ IN WALTER BENJAMIN'S WORKS
}

\author{
REFLEXIONES SOBRE LA NOTION DE EXPERIENCIA \\ EN LA OBRA DE WALTER BENJAMIN
}

\author{
Eduardo Oliveira SANChes ${ }^{1}$ \\ Divino José DA SILVA ${ }^{2}$ \\ ${ }^{1}$ Universidade Estadual de Maringá (UEM), Maringá/PR- Brasil \\ ${ }^{2}$ Universidade Estadual Paulista Júlio de Mesquita Filho (UNESP), \\ Presidente Prudente/SP-Brasil
}

REsumo Tem-se por objetivo, neste estudo, analisar a noção de experiência na obra de Walter Benjamin, como resultado de reflexões realizadas pelo autor sobre o tema, desde a sua juventude até a sua maturidade. Foram demonstradas variações a respeito de qualidades do conceito de experiência, que foram sendo construídas, gradualmente, conforme o autor mudava o seu foco de análise e a observação da realidade social, para tratar de experiência e modernidade. Desse modo, Benjamin voltou-se para o conhecimento como um exercício que evoca o acontecimento, os agoras, os sentidos da aura. Essa dimensão conceitual congrega em si o conhecimento que se constitui a partir de se ter experiências e não apenas de fazê-las, como visa a ciência moderna. Foram utilizados seis ensaios para estabelecer essa análise: "Experiência" (1913); "Sobre o programa da filosofia do porvir" (1918); "Experiência e pobreza" (1933); "O narrador. Considerações sobre a obra de Nicolai Leskov" (1936); "Sobre alguns temas em Baudelaire" (1940) e "Infância Berlinense: 1900" (escrito entre 1926 e 1938).

Palavras-chave: Experiência. Modernidade. Walter Benjamin.

Abstract The aim of this study is to analyze the notion of experience in the work of Walter Benjamin as a result of reflections carried out by the author on the theme from his youth to his maturity. Variations were shown on qualities of the concept of experience, which were 
gradually being built as the author shifted his focus from analysis and observation of social reality to talk of experience and modernity. In this way, Benjamin turned to knowledge as an exercise that evokes the event, the agoras, the senses of the aura. This conceptual dimension brings together the knowledge that is constituted from having experiences and not just doing them as modern science aims. Six trials were used to establish this analysis, they are: "Experience" (1913); "On the program of the philosophy of the future" (1918); "Experience and Poverty" (1933); "The storyteller. Considerations on the work of Nicolai Leskov" (1936); "On some subjects in Baudelaire" (1940) and "Berliner Childhood: 1900" (written between 1926 and 1938).

Keywords: Experience. Modernity. Walter Benjamin.

Resumen Se tiene por objetivo en este estudio analizar la noción de experiencia en la obra de Walter Benjamin como resultado de reflexiones realizadas por el autor sobre el tema desde su juventud hasta su madurez. Se demostró variaciones sobre cualidades del concepto de experiencia, que fueron construidas, gradualmente, conforme el autor cambiaba su foco de análisis y observación de la realidad social para hablar de experiencia y modernidad. De este modo, Benjamín se volvió al conocimiento como un ejercicio que evoca el acontecimiento, los agoreros, los sentidos del aura. Esta dimensión conceptual congrega en sí el conocimiento que se constituye a partir de experiencias y no sólo de hacerlas como apunta a la ciencia moderna. Se utilizaron seis ensayos para establecer este análisis, son ellos: "Experiencia" (1913); "Sobre el programa de la filosofía del porvenir" (1918); "Experiencia y pobreza" (1933); "El narrador. Consideraciones sobre la obra de Nicolai Leskov" (1936); "Sobre algunos temas en Baudelaire" (1940) y "Infancia Berlinesa: 1900" (escrito entre 1926 y 1938).

Palabras clave: Experiencia. Modernidad. Walter Benjamin.

\section{INTRODUÇÃo}

Ao longo da sua vida, Benjamin se dedicou a compreender o seu tempo presente, por intermédio de uma complexa composição reflexiva. As mudanças sociais provocadas pela urbanização e pela industrialização foram o cenário eleito pelo pensador, como ambiente histórico condensador dos resíduos derivados da efervescência moderna, situada nos primórdios do século XIX. No roteiro de viagem, o autor constituiu matizes conceituais das quais se utilizava para realizar sua crítica social, entre as quais observamos a sofisticada teoria da experiência (Erfahrung), que se origina como uma das formas de representação acerca dos impasses inerentes a esse contexto, os quais marcam a relação entre o sujeito e a sociedade, entre a tradição e a modernidade.

É desse contexto que emergem figuras com as quais Benjamin se identificou e procurou explorar, em busca de outra forma de ser, de existir e, assim, de compreender novas roupagens e possibilidades para a ideia de experiência. Encontramos entre elas o flâneur, a 
infância, a juventude, a criança, o cientista, o artista, o poeta. Tais figuras representam uma forma de percepção da realidade alternativa àquela formatada pelos cânones do liberalismo e simbolizam o que Benjamin denominou de novo bárbaro. O bárbaro, por definição, é um ser ainda não civilizado ou que se opõe às regras em uso e que não se submete ao espírito filisteísmo da cultura. O bárbaro é a imagem daquele que ainda não foi completamente pavimentado e impermeabilizado em sua subjetividade e, assim, ainda encontra rotas de fuga à urbanização total dos sentidos da existência, em nome do progresso.

Em seu diagnóstico acerca da experiência, Benjamin estabelece uma série de noções que contribuem para afirmar que, para o autor, não existe um conceito preciso para o termo e sim um conjunto de ideias as quais possibilitam compreender sua densidade e apreendê-la enquanto limiar (BARRENTO, 2012, 2013). Ou seja, experiência, segundo o pensador, é algo que se expressa de modo constelar, pelo arranjo de várias noções por meio das quais a ideia de experiência ganha sentido, em sua obra, e são essas pistas e desvios que buscaremos seguir, neste estudo. Nosso ponto de partida é uma nota redigida por Benjamin, em 1929, sobre o ensaio de 1913, intitulado "Experiência". Ressalta Benjamin:

\footnotetext{
Num de meus primeiros ensaios mobilizei todas as forças da juventude contra a palavra "experiência". E eis que agora essa palavra tornou-se um elemento central de sustentação em muitas de minhas coisas. Apesar disso permaneci fiel a mim mesmo. Pois meu ataque cindiu a palavra sem a aniquilar. $\mathrm{O}$ ataque penetrou até o âmago da coisa (2002, p. 21).
}

A palavra experiência ou a noção de experiência tornou-se cara ao pensador e passou a fazer parte de suas reflexões. Comporemos uma trajetória, visando a expressar a complexidade da noção de experiência, conceito com o qual o pensador afirma ter se encontrado, durante muitos momentos da vida. Há textos específicos nos quais Benjamin se dedicou de forma mais contundente ao tema e outros nos quais tratou, de modo implícito, de elementos que nos ajudam a pensar tal noção. Ensaios como "Experiência" (1913), "Sobre o programa da filosofia do porvir" (1918), "Experiência e pobreza" (1933), "O narrador: considerações sobre a obra de Nicolai Leskov" (1936), "Sobre alguns temas em Baudelaire" (1940) e "Infância Berlinense: 1900" (escrito entre os anos de 1926 e 1938) são exemplos de como esse tema é recorrente na obra do autor alemão e, apesar de não se resumir a esses escritos, concentram-se neles aspectos dos quais nos apropriaremos, a fim de desenvolver a temática que orienta o presente texto.

Para um diálogo mais profícuo acerca do tema da experiência, em Walter Benjamin, recorreremos a um amplo repertório de autores contemporâneos, como Matos (1999, 2007), Löwy (2005), Agamben (2005), Gagnebin (1994, 2013), Steiner (2010), Barrento (2012, 2013), Morey (1990), Mitrovitch (2011), Mazzari (2002), Pereira (1984), Subirats (2001), os quais nos ajudam a compor nossa trajetória, almejando caracterizar o conceito de experiência benjaminiano. 


\section{Sobre os desvios da eXPeriênCIA EM WALter Benjamin}

Uma das primeiras reflexões do pensador sobre o conceito de experiência se inscreve em um contexto no qual Benjamin, por volta dos 20 anos de idade, participava do movimento berlinense denominado Juventude Livre (Jugendbewegung1), e cuja militância o levou a uma rápida passagem pela presidência do grupo, conforme demonstra Steiner (2010). Essa associação de estudantes visava a uma reforma cultural das instituições e costumes. Desse ambiente de juventude militante emerge o ensaio "Experiência", em 1913.

Como menciona Pereira (1984), esse curto texto demonstra uma incisiva crítica ao modo burguês de existência. O desejo de mudanças radicais, no plano cultural, contribuiu para que Benjamin não poupasse em sua crítica a noção de experiência. No ensaio, o termo aparece numa tensão dialética entre o que o pensador chama de "a máscara do adulto" e "os sonhos de juventude".

A experiência como "a máscara do adulto" é, para Benjamin, a imagem da resignação perante a vida e a opressão contra formas e tentativas que tendem a querer transformar essa realidade. Também pode ser retirada dessa imagem a opressão do pensamento do adulto sobre o espírito criativo da juventude. No caso específico, há na juventude uma forma de rebeldia direcionada contra o sistema autoritário e, por que não dizer, contra a própria autoridade do adulto. Conforme afirma o autor, ele mobilizou todas as suas energias de juventude contra as imagens que remetessem à tirania, à subserviência, ao vexatório, em nome de uma suposta experiência.

Evocar a autoridade do "adulto mascarado" no lugar da experiência, segundo Benjamin, impedia, com frequência, a juventude de experimentar outras qualidades da experiência. Para o jovem Benjamin, a máscara do adulto esconde um comportamento que atesta a desilusão a respeito do mundo. Não deixa de ser uma qualidade da experiência e de expressão de autoridade de quem já viveu mais que o jovem. No entanto, tal argumento, como qualidade de experiência, exprime e testemunha o constrangimento que ela causa sobre o jovem considerado inexperiente e o castra, em sua busca por outras possíveis qualidades da experiência.

$\mathrm{O}$ contraponto à mascara do adulto se materializa na imagem dos jovens e dos sonhos de juventude. Assim, assinala o pensador, "conhecemos uma outra experiência. Ela pode ser hostil ao espírito e aniquilar muitos sonhos florescentes. No entanto, é o que existe de mais belo, de mais intocável e inefável, pois ela jamais estará privada de espírito se nós permanecermos jovens" (BENJAMIN, 2002, p. 24-25). Mas o que representa essa solução de compromisso ao impasse em tornar-se um adulto mascarado? Benjamin se refere muito mais a uma ideia ou ideal de juventude do que a uma fase da vida. Ou seja, trata-se da juventude como uma atitude perante a vida.

Esse espírito jovem preservado é, simbolicamente, na visão de Steiner (2010), a manutenção da ideia de juventude como um ethos que nos faz jovens, ao envelhecermos, segundo os argumentos benjaminianos. Está implícita, portanto, uma dimensão ética como significado de permanecermos jovens como condição para termos acesso a essa outra qua- 
lidade da experiência, a qual se contrapõe ao que ele denomina máscara do adulto. O autor não deixa claro em profundidade, nesse ensaio, quais seriam outras diferenças qualitativas entre um momento da experiência e outro.

Se, por um lado, o ensaio condensa um conjunto de reflexões que objetivam dar outra forma ao discurso hegemônico, autoritário, conformista e expressar a rebeldia da juventude e do jovem Benjamin, por outro, a imprecisão e a recusa em chegar a um acabamento maior para a noção de experiência em termos conceituais refletem, nesse momento, a fidelidade com a qual o autor sustenta a própria ideia de experiência que o texto busca conferir expressão. É o adulto que toma a experiência como algo definitivo e acabado, como um sem mais. E justamente a recusa a esse espírito engessado é a atitude, um savoir-faire, a habilidade que persegue o jovem Benjamin e o motiva a compartilhar, como quem dá um conselho a um amigo, acerca de como resistir ao espírito da modernidade: recusar-se a envelhecer; manter-se repleto das inquietações que movem a juventude, sua sensibilidade.

Conforme argumenta Marchi (2011, p. 227), percebemos que há uma tentativa em não subtrair da infância e da juventude o potencial das descobertas e da construção do novo e, nesse caso específico, "em relação à juventude, Benjamin elabora o texto 'Experiência', por meio do qual vai reivindicar, igualmente para os jovens, a possibilidade da experiência plena de sua idade e não um cuidadoso - e sempre pobre de espírito - resguardar-se 'para o futuro'." Não se trata, portanto, de um clichê que versa simplesmente sobre uma juventude questionadora. Ao contrário, tem-se por objetivo o reconhecimento de uma experiência em que cabem a sensibilidade e as possibilidades que residem somente na juventude e nas descobertas desse momento da vida, assim como há uma própria à infância, outra à adolescência, à maturidade, enfim.

Munido desse senso acerca das possibilidades da experiência e já distante do movimento estudantil, Benjamin direciona esforços para recuperar um conceito abrangente de experiência, por intermédio de Kant. Tais críticas se configuraram na forma do estudo intitulado "Sobre o programa da filosofia do porvir", de 1918. Nele, Benjamin se dedica a um exame pormenorizado da experiência, a fim de elaborar um estudo epistemológico a respeito da noção de experiência (STEINER, 2010).

$\mathrm{O}$ estudo exprime as questões que Benjamin se propõe responder, ao retomar o sistema kantiano, em particular as noções de experiência e de conhecimento. Assim, o problema central parece os limites do conhecimento e da experiência sensível, ao vincular essas duas questões ao modelo kantiano, o qual as delimita a uma ordem a priori. Nessa concepção, no fundo, só pode ser objeto do conhecimento aquilo que é objeto de experiência, no espaço e no tempo, submetido às categorias do entendimento, conforme delimitara Kant. O que escapa a essas condições não pode ser conhecido, apenas pensado.

No fundo, Benjamin rompe com essa arquitetônica da razão (MOREY, 1990), pois trabalha com outra noção de tempo que nos conduz à nossa própria existência e que se contrapõe a qualquer projeto de uma razão arquitetônica.

Talvez seja por esse motivo que Benjamin afirma que "temos absolutamente de pensar se a seriedade não objetiva da maneira de ver infantil não poderá ser definida do seguinte 
modo: a criança só conhece por totalidades. Concretamente, substâncias nas quais ela é mesmo capaz de transformar todas as funções e todas as relações" (BENJAMIN, 2013a, p. 130). ${ }^{1}$ Esse comentário se refere aos relatos sobre a criança, em Rua de mão única, e é esclarecedor, se buscarmos entendê-lo no contexto dessa crítica a Kant. Conhecer por totalidades, por meio de uma seriedade não objetiva, escapa à arquitetônica kantiana e reflete outra forma de experimentar o mundo, a qual conduz à existência e à maneira de ser e à sensibilidade da criança em sua infância possível.

Benjamin toma a epistemologia kantiana (em relação ao conceito de experiência) como uma noção a ser superada, assumindo outra compreensão do exercício do pensar. Nesse sentido, propõe ele que as tarefas da filosofia vindoura e do filósofo de seu tempo representam a:

...constitución de un concepto de experiencia más elevado, con fundamentación teorético-epistemológica, dentro del marco del pensamiento kantiano. Y éste, precisamente, debe ser el objetivo de la inminente filosofía: que una cierta tipología del sistema kantiano sea ressaltada y elevada para hacer justicia a una experiencia de más elevado rango y alcance (BENJAMIN, 2001, p. 77).

Mas o que poderia contribuir para alargar o conceito de experiência, a partir de Kant e dos neokantianos, no contexto dessa análise? Nesse ensaio, Benjamin apresenta ao menos três grandes questionamentos, para recompor a noção de experiência:

...la extensión del concepto kantiano de experiencia más allá de su limitación a
las ciencias, la integración del concepto crítico de experiencia del conocimento
al sujeto empírico, o más bien a la pluralidad social e histórica de sujetos em-
píricos, y la ampliación de este concepto nuevo de experiencia al conocimiento
religioso (SUBIRATS, 2001, p. 13).

Os argumentos nos levam a sustentar que Benjamin questionava o que considera reducionista ou aquilo que escapou das proposições kantianas e neokantianas sobre a perspectiva da experiência e do conhecimento, que as aproximaram excessivamente em direção ao positivismo.

Tais elementos poderiam ajudar a recompor a noção de experiência, de sorte a incorporar outras qualidades possíveis e compatíveis com a ideia da experiência, porém, sem excluir os pressupostos da ciência matemática. Dessa forma, podemos sustentar que se concretiza, neste estudo de auto-orientação, um reposicionamento histórico das ideias kantianas a respeito do conceito de experiência, e se inauguram inquietações, cujo trabalho Benjamin (2002) sustenta ter sido um aspecto recorrente em sua obra - cindir a noção de experiência, porém, sem aniquilá-la.

\footnotetext{
Fonte: Arquivo Benjamin, manuscrito 914 - a citação que fizemos em nosso texto segue os comentários de Barrento (2013a). O tradutor incluiu uma série de análises particulares, com comentários do autor alemão, como é o caso.
} 
Nos avanços e recuos, desvios e atalhos trilhados por Benjamin, em suas reflexões sobre a experiência, em um ensaio posterior, datado de 1933, afirma o autor: "está claro que as ações das experiências estão em baixa" (BENJAMIN, 1994, p. 113), pois, para ele, o meio social que nos ajudaria a entender seu sentido forte, a tradição, encontra-se soterrado sob os escombros erigidos pelo mundo moderno. É a mesma tradição, a qual, quando rompida, separou pais e filhos, ao expropriar da família a função mediadora que existia no ato de construir os brinquedos infantis ou de socializar a infância (BENJAMIN, 2002).

Agamben (2005) situa essa problemática, enfatizando a dicotomia entre experiência e conhecimento. Ter e fazer experiências, eis modos bastante distintos sobre a relação entre $o$ humano e a vida. Na modernidade, a emancipação do conhecimento se dá por sua redução aos experimentos científicos, como meio que garante a precisão do conhecimento e de suas leis. Na tradição, a experiência ocorre de forma partilhada, por intermédio do compartilhamento de conhecimentos de maneira marcadamente intergeracional, por meio da narração. O mais velho concentrava em si a autoridade de quem já viveu uma vida e, por conseguinte, se tornava um registro vivo da história (AGAMBEN, 2005).

Em tal concepção, "ela [a narrativa] sempre fora comunicada aos jovens. De forma concisa, como a autoridade da velhice, em provérbios; de forma prolixa, com a sua loquacidade, em histórias, muitas vezes como narrativas de países longínquos, diante da lareira, contadas a pais e netos" (BENJAMIN, 1994, p. 112). Eram histórias transmitidas de modo oral e coletivo, cuja experiência era tecida de modo quase artesanal, na relação entre ouvintes e narradores. Nelas estavam contidos importantes ensinamentos, cuja mediação entre o passado e o presente e seu conteúdo latente necessitava ser interpretado ou reinterpretado ao ser contado novamente, ganhando, assim, sentido no âmbito do coletivo. Nesse caso:

\footnotetext{
...a experiência se inscreve numa temporalidade comum a várias gerações. Ela supõe, portanto, uma tradição compartilhada e retomada na continuidade de uma palavra transmitida de pai a filho; continuidade e temporalidade das sociedades "artesanais" diz Benjamin em "O Narrador", em oposição ao tempo deslocado e entrecortado no capitalismo moderno (GAGNEBIN, 2013, p. 57).
}

Benjamin chama a atenção para a temporalidade como noção elementar para se compreender os sentidos da experiência (Erfahrung), na tensão entre tradição e modernidade. Na tradição, essa questão tem uma conotação de longa duração: é o tempo das conversas, do debate em praça pública, da produção artesanal, da coincidência entre o conhecimento e sua aplicação prática - o que tem valor é aquilo que perdura e não o transitório. Nessa noção de temporalidade, as histórias narradas têm um efeito evidente na comunidade, pois elas não são simplesmente ouvidas, são também seguidas. "Acarretam uma verdadeira formação (Bildung), válida para todos os indivíduos de uma mesma coletividade" (GAGNEBIN, 2013, p. 57).

Aqui, a experiência coletiva da narração contribuía para expandir a dimensão subjetiva no exercício do convívio da vida em comunidade. Forma e conteúdo se complementam. Para o narrador, afirma Benjamin (1994), há um desafio que faz dele uma figura muito importan- 
te, no contexto da tradição, que é contar novamente uma história, uma arte que se aprimora ao narrar. No exercício coletivo da experiência do tédio no cotidiano, do fazer repetitivo do trabalho artesanal, o narrador emergia como um anjo profano, resgatando a todos desse tédio. Nessa repetição, tanto do trabalho como da narração, constituía-se a comunidade.

Se a noção de experiência, a qual Benjamin se dedica a compreender, está no apogeu da anulação dos seus efeitos, é justamente pelo fato de as sociedades tradicionais estarem à margem de seu desaparecimento. $\mathrm{O}$ capital, ao entoar suas trombetas e seus tambores, anuncia que a modernidade chegou disposta a se estabelecer rapidamente, em nome do progresso, sustentado pelo experimento. Nesse contexto, não há tempo e espaço para tecer o fio coletivo da vida que unia sujeito e sociedade, por meio da narração.

Para situar a noção que se opõe à tradição, ele demonstra que a narração começa a ter seu equivalente moderno radicalizado em uma nova forma de comunicação, cujo grande foco é a informação. Esta tem como mecanismo de assimilação a verificação imediata. Segundo o autor, a informação deve ser de alta palatabilidade e sua leitura deve proporcionar ao leitor a compreensão do fato rapidamente: "Todos os dias a cidade volta a prometer-nos, e todas as noites me ficava a dever o prometido", assevera Benjamin (BENJAMIN, 2013a, p. 106). Continua o autor: "se aconteciam, quando eu chegava ao local já eles tinham desaparecido, como deuses que só concedem breves instantes aos mortais. Uma vitrine quebrada, a casa de onde se tinha tirado um morto" (BENJAMIN, 2013a, p. 106).

Com a aceleração do tempo e as transformações do meio produtivo, reduziu-se a comunicabilidade das experiências, bem como, a arte de narrar, como se fazia no contexto da tradição. Na modernidade burguesa, capitalista, industrial, o relógio transforma-se em títere do tempo e, com margem nessa premissa, enfatiza o pensador, na Tese VII, o tempo se tornou "homogêneo e vazio" (BENJAMIN, 1994, p. 228). Essa expressão de temporalidade, cujo ruído ganha ressonância no cotidiano do contexto urbano das metrópoles modernas, afere também sua característica de instante, de efêmero. Nesse sentido, Benjamin propõe um atributo novo em oposição à experiência (Erfahrung), como sentido forte do termo: a vivência (Erlebnis).

$\mathrm{Na}$ tradição, o cotidiano não tinha esse caráter privado sobre o vivido. A experiência se transformava, segundo esse sentido de orientação na modernidade, momento em que se criaram os mecanismos que resultaram em uma limitação, para que os fatores coletivos e exteriores à vida privada se juntassem à experiência. A informação como mercadoria transubstancia essa noção, na forma dos jornais e dos reclames. Na informação jornalística, tipo moderno de narrativa acerca do vivido, há limitações que inviabilizam ao fato informado transcender, de modo a ser incorporado pelos leitores.

Essa nova relação que se imprime no cotidiano não se restringe ao jornal impresso, mas se estende à vida humana, por meio dos elementos construídos no seio da civilização capitalista e expressos em suas inúmeras fantasmagorias do presente, no sentido benjaminiano do termo. O pensador, então, propõe que a relação do humano com a Modernidade se reconfigura enquanto vivência de choque. Benjamin (1989, p. 110) explica da seguinte maneira tal relação: "O fato do choque ser assim amortecido e aparado pelo consciente 
emprestaria ao evento que o provoca o caráter de experiência vivida em sentido restrito. E, incorporado imediatamente este evento ao acervo das lembranças conscientes, o tornaria estéril para a experiência" (BENJAMIN, 1989, p. 110).

A vivência (Erlebnis), nesse contexto, ao transformar-se na nova conduta social, reduz ou enfraquece os sentidos da experiência (Erfahrung). O dado coletivo da tradição é substituído por outra forma de expressão de grupo, a multidão civilizada. As massas, assim, se configuram como "multidão amorfa de passantes" (BENJAMIN, 1989, p. 113), cujos sujeitos se esforçam em abrir caminhos entre si, como se não tivessem absolutamente nada em comum uns com os outros, a não ser os esbarrões e solavancos trocados no ir e vir dos passantes. "A vivência de choque sentida pelos transeuntes na multidão corresponde à 'vivência' do operário com a máquina" (BENJAMIN, 1989, p. 126).

Por meio de seu diagnóstico sobre o moderno e os limites da experiência no tempo presente, questiona o pensador, no ensaio "Experiência e pobreza":

Que foi feito de tudo isso? Quem encontra ainda pessoas que saibam narrar algo direito, contar histórias como elas devem ser contadas? Que moribundos dizem hoje palavras tão duráveis que possam ser transmitidas como um anel, de geração em geração? Quem é ajudado, hoje, por um provérbio oportuno? Quem tentará, sequer, lidar com a juventude invocando sua experiência? [...]. Qual o valor do nosso patrimônio cultural, se a experiência não mais o vincula a nós? (BENJAMIN, 1994, p. 114-115).

Se, na modernidade, não nos é mais permitido historicamente viver no ambiente social da tradição, mas nos é dado como legado o contexto do choque como substituto, estamos fadados a não realizar mais experiências no sentido da Erfahrung? O autor oferece uma solução instigante para esse impasse moderno. No mesmo ensaio, "Experiência e pobreza", o filósofo sugere que seria fundamental, primeiramente, reconhecer a miséria social decorrente do capitalismo e confessar nossa pobreza de experiência. O resultado seria um novo tipo humano que conclama um novo início, a partir das tábulas rasas do moderno, "a partir para frente, a começar de novo, a contentar-se com pouco, a construir com pouco" (BENJAMIN, 1994, p. 116), figura a qual o autor chama de "o novo bárbaro". Descartes, Einstein, Klee, Brecht são citados como exemplo de sujeitos portadores de uma sensibilidade condizente com a alegoria do "novo bárbaro".

Para esses bárbaros modernos, aos quais Benjamin atribui sentido positivo, o desafio foi o de conceber, com base na vivência do choque, alguma experiência que contribuiria para a criação de algum sentido possível para a realidade. Fazer emergir a Erfahrung, a partir da Erlebnis, é o mesmo que retirar do dado vivido, de modo individual, alguma máxima de orientação coletiva.

Ao olharmos por esse ângulo, Benjamin não exclui por completo as possibilidades de que a Erfahrung possa existir na modernidade, todavia, declara que o trabalho é árduo e, em função da miséria moderna, do senso entorpecedor das massas civilizadas, do contexto inexorável da Erlebnis, desse local podem emergir sentidos coletivos sobre o moderno, 
como os realizados por ele, nos ensaios de "Infância Berlinense: 1900". Sua crítica, a nosso ver, reside nas limitações trazidas pela sociedade capitalista industrial, em viabilizar, no ambiente das relações cotidianas, caminhos que permitam aos sujeitos encontrarem o significado de uma vida compartilhada.

Nessa vertente, Mitrovitch (2011) afirma que se trata, “assim, de uma reflexão sobre a relação desse conceito [a Erfahrung] com o de vivência (Erlebnis), compreendendo que a experiência não exclui a vivência, mas a pressupõe e a ultrapassa" (MITROVITCH, 2011, p. 79).

O cotidiano precário, portanto, reduzido ao choque, ao efêmero, ao volátil, ao transitório, não é o fim, como prescreve o mundo fantasmagórico do capital industrial, mas o início da reconstrução dos sentidos de uma vida coletiva na modernidade. Benjamin (1994, p. 87-88) argumenta que essa postura frente aos impasses da modernidade deve "rejeitar a imagem do homem tradicional, solene, nobre, adornado com todas as oferendas do passado" e nos voltarmos "para o homem contemporâneo, despojado e gritando como a um recém-nascido nas fraldas sujas deste tempo". Afirma, portanto, que nossa pobreza moderna viabiliza caminhos para que algo novo surja, algo que nos possibilite "sobreviver à cultura". O recém-nascido é o potencial do humano, um devir que pode ser diferente do que se tem. Começar das "tábulas rasas" ganha sentido, se pensarmos nelas como as vivências precárias cotidianas de onde pode emergir algum sentido para a vida moderna, a ser ainda elaborado, transformando-se em um exercício profundo, o qual pode ligar nossas tramas subjetivas individuais àquelas de cunho social coletivo.

"Escovar a história a contrapelo", "buscar os cacos da história", "saudar o novo bárbaro", "sorrir às multidões, emprestar uma alma às massas", "tomar o moderno nu", "despertar do sono", enfim, são todas formas de o pensador nos propor o exercício de elaboração do nosso passado mais recente, o mundo moderno. Nessa tarefa, torna-se fundamental reinventar os sentidos do moderno, por meio de uma reflexão sobre e a partir da noção de choque e da ideia de vivência. Entre os bárbaros modernos, aos quais o pensador associa um valor positivo, temos a figura do flâneur, dimensionada pela poesia lírica de Baudelaire e da crítica a Paris do século XIX.

$\mathrm{Na}$ atitude do flâneur, "as distâncias dos países e dos tempos irrompem na paisagem e no momento" (BENJAMIN, 1994, p. 189), nesse caso, "a cidade é o autêntico chão sagrado da flânerie" (BENJAMIN, 1994, p. 191). Para essa imagem, salienta o filósofo, há certa dialética na atitude do flâneur, pois, em meio à massa de transeuntes, ele é, "por um lado, o homem que se sente olhado por tudo e por todos, simplesmente o suspeito; por outro, o totalmente insondável, o escondido" (BENJAMIN, 1994, p. 190). A multidão e a urbanização modernas, nesse cenário, são expressões de uma profunda e nova fisiognomia do tempo presente, que demonstram suas metamorfoses.

Se, por um lado, não nos é mais possível a tradicional experiência (Erfahrung) da vida, Benjamin nos mostra um caminho possível, a começar pela pobreza contida no choque das vivências (Erlebnis). "Não há nada de especial em não nos orientarmos numa cidade. Mas perdermo-nos numa cidade, como nos perdemos numa floresta, é coisa que 
precisa se aprender", afirma Benjamin (2013a, p. 78), ao escrever sobre "Tiergarten", seu parque favorito na infância e nome de um dos ensaios de "Infância Berlinense: 1900". Essa imagem nos permite uma gama de reflexões que podem nos ajudar a sermos também novos bárbaros, a fazer a "botânica do asfalto". Para seguir em direção a seu projeto a respeito da noção de experiência, Morey (1990) assinala que Benjamin constituiu um senso ético filosófico, que o comentarista denomina la vía del Paseante, cuja imagem mais adequada, para ela, é a que se encontra nos escritos de Baudelaire e que se transubstancia na análise benjaminiana da figura do flâneur:

\footnotetext{
Para salvaguardar la dignidad de lo que se aparece, Benjamin optará por una vía divergente, la vía del Paseante, y declarará entonces: que (a) las formas pertenecen al dominio de un ser sin intencionalidad, y (b) que para acceder a la experiencia de su verdad (verdad que, en tanto que trance, aquí resulta difícil distinguir de la experiencia misma de la belleza) es necesario "un ser que iguale por su ausencia de intencionalidad el ser simple de las cosas" (Cfr. El origen del drama barroco alemán) (MOREY, 1990, p. 7).
}

Tais assertivas de Morey (1990), acerca da jornada benjaminiana para o conceito de experiência, são feitas pelo comentarista, ao problematizar as reflexões contidas no estudo intitulado "Sobre o programa da filosofia do porvir", de 1918. Nessa vertente, Morey (1990) afirma que certas questões levantadas pelo jovem Benjamin a respeito de Kant só seriam, de alguma forma, respondidas mais tarde, ao ser escrito o ensaio sobre Baudelaire. Assim, em Benjamin, toda a filosofia se situaria entre duas tendências: "(a) buscar la certeza de un conocimiento que permanece y reivindicar el valor intemporal del saber, frente a (b) restaurar la dignidad de la experiencia que pasa, y establecer el valor de la experiencia temporal" (MOREY,1990, p. 7). Portanto, torna-se fundamental, ao pensamento filosófico de Benjamin, a ética do flâneur que se apresenta com uma forma de recuperar a importância daquilo que é singular e fugidio, passageiro e temporário, o casual, o acontecimento também como fonte da experiência. Em certo sentido, são todos elementos que encontramos igualmente na sensibilidade e no modo de existir da criança e da juventude.

Como ética do flâneur e princípio filosófico para o sentido da experiência que Benjamin se propõe, Morey (1990) desenvolve uma espécie de minuta, denominada "el método del paseante", cuja finalidade é caracterizar, de forma programática, as possibilidades que a experiência própria do passeante inauguraram, a partir do pensamento benjaminiano.

Enquanto sentido da experiência do passeante, isso significa recuperar a experiência impactante, por vezes aterradora, inebriante ou esfuziante, porém, ainda assim frágil das primeiras coisas da vida, das descobertas, do inusitado de nossa existência. Remete à primeira vez em uma cidade, a estar em um lugar sem conhecer a língua, ao primeiro dia na escola, à primeira relação sexual, ao primeiro beijo, ao dia em que deixamos de ser filhos e nos tornamos pais ou mães, a segurar no colo um ser humano recém-chegado e logo, ao nascer, escutar seu choro e não saber bem o que fazer. A questão está em experimentar algo pela primeira vez, olhar sem prévias, sem registros anteriores, como o olhar da criança, sem a hegemonia do a priori do imperativo kantiano. 
Ter a experiência do acontecimento fora de um regime arquitetônico a priori, de um projeto preestabelecido, compreende uma forma de atenção específica para o mundo. Uma atenção flutuante, a qual rompe com a vontade de reconhecimento e está comprometida com a abertura para as possibilidades de experimentação que o acontecimento pode proporcionar ao passeante.

Podemos asseverar, a partir do que está posto, que a experiência do passeante é aquela de quem busca os rastros das vivências em um tempo em transformação, em que as coisas nos escapam pela velocidade que a modernidade nos obriga a transitar pela vida nos grandes centros urbanos - por que não dizer, a transitar pelas redes sociais e pelo excesso de informação que nos chega de todos os lados. O passeante caminha em um limiar no qual o mundo em transformação impõe a constituição e a reconstituição do aparato perceptual, em direção a suportar a experiência de choque e o ambiente das vivências. Entre choques e vivências, o urbano e a metrópole, eis o habitat indispensável ao passeante.

\section{CONSIDERAÇÕES FINAIS}

O objetivo deste estudo foi analisar a noção de experiência, na obra de Walter Benjamin, como resultado de reflexões realizadas pelo autor sobre o tema, desde sua juventude e até sua maturidade. Demonstraram-se variações acerca de qualidades do conceito de experiência, que foram sendo construídas, gradualmente, conforme o autor mudava seu foco de análise e observação social, para refletir a respeito da relação experiência e modernidade. Nesse percurso, encontramos elementos para afirmar que Benjamin reconheceu a noção de indivíduo moderno como vivência necessária para se chegar a alguma experiência, na modernidade, não no sentido da tradição, mas como aquela que governa a mente inquieta do novo bárbaro, ao qual Benjamin atribui um valor positivo. Esse, por ainda não ter sido pavimentado por completo em sua subjetividade, carrega consigo espaços para profanar a ordem estabelecida. Nos ensaios sobre a noção de experiência, observamos esse tipo de registro, apesar de a grande marca ser o declínio da experiência da tradição.

Se tomarmos os argumentos seguindo a cronologia de sua produção, verificamos que, na juventude, Benjamin criticou, de modo severo, a experiência do adulto, chamando-a de "máscara do adulto", em contraposição aos "sonhos da juventude". Nesse ensaio, há uma valorização da experiência possível de ser vivida apenas na juventude e sabotada pelos valores morais que subjaziam a tal máscara a que o adulto se referia como experiência. Já nos textos da maturidade, ele reivindica aos jovens ouvidos que um dia se permitiram ouvir os conselhos dos mais velhos. Essa aparente contradição nos demonstra um completo e profundo respeito ético para a experiência do novo bárbaro, pois ela qualifica de modo mais agudo a noção de infầncia do homem, quando evidencia o princípio de não envelhecer em espírito, enquanto o corpo avança na escala do tempo.

Há nesse percurso, no mínimo, uma valorização dessas especificidades, como se fossem a aura possível, remanescente, em uma vida sob o signo da mercadoria. Nesse sentido, 
entendemos que Benjamin indica que, para cada momento da vida, existem experiências que só podem ser vividas como agora. Gagnebin (2014) chama isso de ritos limiares e experiências limiares, ou seja, situações que fazem parte dos rituais de passagem, como é a puberdade, o nascer e o morrer. Como exemplo disso, parafraseamos a assertiva feita pelo autor alemão em um de seus textos, no qual reflete sobre a vida dos jovens - não é a mesma coisa fugir da casa dos pais, quando se tem 15 anos de idade e quando se tem 21. Quem nunca o fez aos 15 perdeu a chance de viver essa rebelde aventura adolescente. ${ }^{2}$

Com esse rompante juvenil, chegamos à ética do passeante (MOREY, 1990), porque ela move tanto o flâneur como a criança da Infância Berlinense, vivida por Benjamin no limiar do século, em 1900. De forma labiríntica, por meio do deambular, conhece-se a cidade e suas múltiplas passagens, tanto em Paris como em Berlim. A ética do passeante demonstra não apenas que há uma experiência ligada ao crivo geracional, mas que o flâneur aprendiz, a criança da infância que cada um tem dentro de si, é o princípio do que poderá vir a ser o flâneur adulto de cada um. Para algumas crianças, simplesmente, foi vetada qualquer possibilidade de viver a infância moderna, seja pelo trabalho infantil, seja pelos abusos físicos, sexuais, mentais ou psicológicos. A elas nos resta não esquecer jamais o que lhes foi feito. Resta-nos repensar a vida moderna que deixou, como legado para essas crianças e adultos, a triste invisibilidade consequente da completa integração ao mundo do trabalho e às demandas do consumo.

\section{REFERÊNCIAS}

AGAMBEN, Giorgio. Infância e História: destruição da experiência e origem da história. Belo Horizonte: Editora UFMG, 2005.

BARRENTO, João. Walter Benjamin: limiar, fronteira e método. Olho d'água. Revista do Programa de Pós-Graduação em Letras da UNESP, São José do Rio Preto, v. 4, n. 2, p. 41-51, jul./dez. 2012.

BARRENTO, João. Limiares sobre Walter Benjamin. Florianópolis: Ed. da UFSC, 2013.

BENJAMIN, Walter. Reflexões: a criança, o brinquedo, a educação. São Paulo: Summus, 1984.

BENJAMIN, Walter. Obras escolhidas II. São Paulo: Brasiliense, 1989.

2 No aforismo de Rua de mão única, intitulado "Volte! Está tudo perdoado", o autor analisa a felicidade no limiar entre a liberdade e o abandono do aconchego do lar paterno, a partir da experiência de fugir de casa quando adolescente. A ousadia em sair da zona de conforto, segundo Benjamin, é condição para se ter a experiência da felicidade que somente é possível ao se viver o não planejado, os agoras. O texto diz: "Pois somente o que já sabíamos ou exercitávamos aos 15 anos representará um dia os nossos atrativos. E, por isso, uma coisa jamais pode ser reparada: ter perdido a oportunidade de fugir da casa de seus pais", pois: "de 48 horas de desabrigo nesses anos condensa-se como numa barrela o cristal da felicidade da vida" (BENJAMIN, 2002, p. 103). 
BENJAMIN, Walter. Obras escolhidas I. São Paulo: Brasiliense, 1994.

BENJAMIN, Walter. Sobre el programa de la filosofía venidera. In: Para una crítica de la violencia y otros ensayos. Madri: Taurus, 2001, p. 75-84.

BENJAMIN, Walter. Reflexões: sobre a criança, o brinquedo e o brincar, a educação. São Paulo: Duas Cidades; ed. 34, 2002.

BENJAMIN, Walter. Passagens. Belo Horizonte: Editora UFMG, São Paulo: Imprensa Oficial do Estado de São Paulo, 2007.

BENJAMIN, Walter. Rua de mão única: Infância berlinense, 1900. Belo Horizonte: Autêntica, 2013.

GAGNEBIN, Jeanne Marie. Pré-fácio - Walter Benjamin e a história aberta. In: BENJAMIN, Walter. Obras escolhidas I. São Paulo: Brasiliense, 1994, p. 7-19.

GAGNEBIN, Jeanne Marie. História e narração em W. Benjamin. São Paulo: Perspectiva, 2013.

LÖWY, Michael. Walter Benjamin - Aviso de Incêndio: uma leitura das teses "Sobre o conceito de história”. São Paulo: Boitempo, 2005.

MATOS, Olgária. O iluminismo visionário: Benjamin, leitor de Descartes e Kant. São Paulo: Brasiliense, 1999.

MATOS, Olgária. Baudelaire: antítese e revolução. Alea, v. 9, n. 1, p. 88-101, jan./jul. 2007.

MAZZARI, Marcos Vinícius. Nota introdutória. In: BENJAMIN, Walter. Reflexões: sobre a criança, o brinquedo e o brincar, a Educação. São Paulo: Duas Cidades; ed. 34, 2002.

MITROVITCH. Caroline. Experiência e Formação em Walter Benjamin. São Paulo: Editora UNESP, 2011.

MOREY, Miguel. Kantspromenade, invitación a la lectura de Walter Benjamin. Revista Creación. Madrid, n. 1, p. 1-11, abr. 1990. Disponível em: http://www.mediafire.com/ view/1422414gq39f343/BBF006.pdf. Acesso em: 24 fev. 2016.

PEREIRA, Uilcon. Apresentação da edição brasileira. In: BENJAMIN, Walter. Reflexões: sobre a criança, o brinquedo, a educação. São Paulo: Summus, 1984, p. 9-12.

STEINER, Uwe. Walter Benjamin: an introduction to his work and thought. Chicago; Londres: The University of Chicago Press, 2010. 
SUBIRATS, Eduardo. Introducción por Eduardo Subirats. In: Benjamin, Walter. Para una crítica de la violencia y otros ensayos. Madri: Taurus, 2001, p. 9-19.

\section{Dados dos Autores}

\section{Eduardo Oliveira Sanches}

Doutor em Educação pela Universidade Estadual Paulista Júlio de Mesquita Filho.Presidente Prudente/SP-Brasil. Professor da Universidade Estadual de Maringá. Maringá/PRBrasil. eduardo.uem@hotmail.com.

\section{Divino José da Silva}

Doutor em Educação pela Universidade Estadual Paulista Júlio de Mesquita Filho. Presidente Prudente/SP-Brasil. Professor da Universidade Estadual Paulista Júlio de Mesquita Filho.Presidente Prudente/SP-Brasil. divino.js21@uol.com.br.

Submetido em: 13-6-2017

Aceito em: 8-11-2019 